Remedi at i on of toxi c metal cont ami nat ed soi I by washi ng with bi odegr adable ami nopol ycar boxyl at e chel ant s

\begin{tabular}{|c|c|}
\hline 著者 & $\begin{array}{l}\text { Begum Zi nnat A., Rahman I smai I M M, Tat e } \\
\text { Yousuke, Sawai Hi karu, Naki Ter uya, Hasegawa } \\
\text { H r oshi }\end{array}$ \\
\hline $\begin{array}{l}\text { jour nal or } \\
\text { publ i cat i on titl e }\end{array}$ & Chenospher e \\
\hline vol une & 87 \\
\hline nunber & 10 \\
\hline page $r$ ange & $1161-1170$ \\
\hline year & 2012-06-01 \\
\hline URL & ht t p: //hdl . handl e. net /2297/30367 \\
\hline
\end{tabular}




\section{Remediation of Toxic Metal Contaminated Soil by Washing with Biodegradable Aminopolycarboxylate Chelants}

Zinnat A. Begum, ${ }^{\mathrm{a}, *}$ Ismail M. M. Rahman, ${ }^{\mathrm{a}, \mathrm{b}}$ Yousuke Tate, ${ }^{\mathrm{a}}$ Hikaru Sawai, ${ }^{\mathrm{a}}$ Teruya Maki, ${ }^{\mathrm{c}}$ Hiroshi Hasegawa $^{\mathrm{c}, *}$

${ }^{a}$ Graduate School of Natural Science and Technology, Kanazawa University, Kakuma, Kanazawa 920-1192, Japan

${ }^{\mathrm{b}}$ Department of Chemistry, Faculty of Science, University of Chittagong, Chittagong 4331, Bangladesh

${ }^{\mathrm{c}}$ Institute of Science and Engineering, Kanazawa University, Kakuma, Kanazawa 920-1192, Japan

*Author(s) for correspondence.

E-mail: zinnat.ara@gmail.com (Z.A. Begum); hhiroshi@t.kanazawa-u.ac.jp (H. Hasegawa). Tel/ Fax: +81-76-234-4792 


\section{Abstract}

Ex situ soil washing with synthetic extractants such as, aminopolycarboxylate chelants (APCs) is a viable treatment alternative for metal-contaminated site remediation. EDTA and its homologs are widely used among the APCs in the ex situ soil washing processes. These APCs are merely biodegradable and highly persistent in the aquatic environments leading to the post-use toxic effects. Therefore, an increasing interest is focused on the development and use of the eco-friendly APCs having better biodegradability and less environmental toxicity. The paper deals with the results from the lab-scale washing treatments of a real sample of metal-contaminated soil for the removal of the ecotoxic metal ions ( $\mathrm{Cd}, \mathrm{Cu}, \mathrm{Ni}, \mathrm{Pb}, \mathrm{Zn})$ using five biodegradable APCs, namely [S,S]ethylenediaminedisuccinic acid, imminodisuccinic acid, methylglycinediacetic acid, DL-2-(2carboxymethyl)nitrilotriacetic acid (GLDA) and 3-hydroxy-2,2'-iminodisuccinic acid. The performance of those biodegradable APCs was evaluated for their interaction with the soil mineral constituents in terms of the solution $\mathrm{pH}$ and metal-chelant stability constants, and compared with that of EDTA. Speciation calculations were performed to identify the optimal conditions for the washing process in terms of the metal-chelant interactions as well as to understand the selectivity in the separation ability of the biodegradable chelants towards the metal ions. A linear relationship between the metal extraction capacity of the individual chelants towards each of the metal ions from the soil matrix and metal-chelant conditional stability constants for a solution $\mathrm{pH}$ greater than 6 was observed. Additional considerations were derived from the behavior of the major potentially interfering cations ( $\mathrm{Al}, \mathrm{Ca}, \mathrm{Fe}, \mathrm{Mg}$, and $\mathrm{Mn}$ ), and it was hypothesized that use of an excess of chelant may minimize the possible competition effects during the single-step washing treatments. Sequential extraction procedure was used to determine the metal distribution in the soil before and after the extractive decontamination using biodegradable APCs, and the capability of the APCs in removing the metal ions even from the theoretically immobilized fraction of the contaminated soil was observed. GLDA appeared to possess the greatest potential to decontaminate the soil through ex situ washing treatment compared to the other biodegradable chelants used in the study.

\section{Keywords}

Soil remediation; Toxic metals; Ex situ washing; Aminopolycarboxylate chelants; Biodegradable; Sequential extraction 


\subsection{Introduction}

Soil contamination with heavy metals derived from various anthropogenic activities, including agricultural practices, industrial activities and waste disposal is a worldwide concern. Soil washing is one of the few enduring treatment alternatives, which uses either or both physical and chemical processes, to confine the contaminants in soils (Peters, 1999; Dermont et al., 2008). Soil decontamination by washing treatment can be accomplished through either in situ or ex situ operations. Aminopolycarboxylate chelants (APCs) such as, EDTA and its homologs are commonly utilized in the ex situ soil washing processes due to their ability to interact with the majority of toxic metals (Leštan et al., 2008; Hasegawa et al., 2010; Hasegawa et al., 2011). However, the ecoenvironmental consequences due to the release of APCs to the surroundings become an issue of concern (Rahman et al., 2010). The lethal exposures resulting from the APCs are likely to persist for a longer period because of their poor photo-, chemo- and biodegradability (Egli, 2001; Nowack, 2002) and, in most cases, an increase in the threshold values for toxic effects may be observed with metal complexation (Sillanpää and Oikari, 1996). Therefore, search for the replacement options of the classical APCs with eco-friendly biodegradable variants became a topic of interest for the treatment of heavy metal-contaminated soils (Tandy et al., 2004; Hauser et al., 2005; Zhang et al., 2008). Nitrilotriacetic acid (NTA) and [S,S]-ethylenediaminedisuccinic acid (EDDS) have been proposed as the biodegradable replacement for EDTA in soil washing (Pichtel and Pichtel, 1997; Vandevivere et al., 2001; Tandy et al., 2004), while the possibility of adverse health effects from NTA restricts its wide use (Ebina et al., 1986).

Comparative performance of EDTA with other chelating agents were reported for calcareous type soils from contaminated sites (Pichtel and Pichtel, 1997; Steele and Pichtel, 1998; Tandy et al., 2004) or artificially contaminated soil samples (Lim et al., 2004). High organic-matter content in the soil affects the washing processes because the high molecular weight humus organic substances have a high affinity for metals and form water-insoluble metal complexes (Peters, 1999). Influence of organic matter on the removal of heavy metals by soil washing techniques employing sodium metabisulfite and EDTA solutions is reported (Abumaizar and Khan, 1996).

The present study evaluates and compares the effectiveness of different biodegradable APCs for 
the washing treatment of organic-rich soil with that of EDTA. The biodegradable APCs are: EDDS, imminodisuccinic acid (IDSA), methylglycinediacetic acid (MGDA), DL-2-(2-carboxymethyl) nitrilotriacetic acid (GLDA) and 3-hydroxy-2,2'-iminodisuccinic acid (HIDS). Washing experiments were carried out using a certified organic-rich soil sample under controlled $\mathrm{pH}$ conditions and fixed chelant:metal ratio. Comparative stability constants of metal-chelant complexes were used to comprehend the extraction pattern of APCs. Solid phase speciation of soils before and after the extraction treatment was conducted to understand the effects of metal distribution and competition between the soil fractions, and the interference associated with the extraction of metals.

The objective of the work is to provide an insight on the behavior of the different biodegradable chelants for the removal of metals from the organic-rich contaminated soil, which was not reported before. Furthermore, biodegradable GLDA and HIDS are evaluated for the first-time for soil washing as an alternative of EDTA and its homologs.

\subsection{Experimental}

\subsection{Materials}

\subsubsection{Soil sample}

An organic-rich soil reference material BCR 700 from EC-JRC-IRMM (European Commission Joint Research Centre, Institute of Reference Materials and Measurements) was used. The soil was collected from a German agricultural research station and has significantly increased metal concentrations due to long periods of sewage sludge amendment. The soil sample was carefully homogenized and bottled, and was certified for EDTA and acetic acid-extractable trace element $(\mathrm{Cd}$, $\mathrm{Cr}, \mathrm{Cu}, \mathrm{Ni}, \mathrm{Pb}$, and $\mathrm{Zn}$ ) contents following collaboratively tested and harmonized procedures (Pueyo et al., 2001; Rauret et al., 2001).

\subsubsection{Aminopolycarboxylate chelants}

EDTA from Wako Pure Chemical, Osaka, Japan; EDDS from Chelest, Osaka, Japan; IDSA (commercial name: Baypure CX 100) from LANXESS AG, Leverkusen, Germany; MGDA (commercial name: Trilon M) from BASF, Ludwigshafen, Germany; GLDA (commercial name: Dissolvine GL) from AkzoNobel, Amsterdam, Netherlands; and HIDS from Nippon Shukubai, Tokyo, Japan was used. EDTA was used as the reference compound with which the other APCs 
were compared. Structures and $\log K_{\mathrm{ML}}$ values of the APCs used in the study along with their predominant forms in the 1:1 metal-chelant assay mixture are given in Table 1.

\subsubsection{Other materials}

Analytical reagent grade chemicals were used throughout the study without further purification. Standards for metal concentration measurements were prepared from a multi-element solution (PlasmaCAL, SCP Science, Québec, Canada) in 5\% $\mathrm{HNO}_{3}$. Solutions of working standards ranging from $\mu \mathrm{M}$ to $\mathrm{mM}$ were prepared by dilution on a weight basis. Either $\mathrm{HCl}$ or $\mathrm{NaOH}(1 \mathrm{M})$ was used to adjust the experimental $\mathrm{pH}$. Acetic acid/sodium acetate $\left(\mathrm{CH}_{3} \mathrm{COOH} / \mathrm{CH}_{3} \mathrm{COONa}\right.$; Kanto Chemical, Tokyo, Japan), $N$-2-hydroxyethylpiperazine- $N$ '-2-ethanesulfonic acid $\left(\mathrm{C}_{8} \mathrm{H}_{18} \mathrm{~N}_{2} \mathrm{O}_{4} \mathrm{~S}\right.$; Nacalai Tesque, Kyoto, Japan), and $N$-cyclohexyl-3-aminopropanesulfonic acid $\left(\mathrm{C}_{9} \mathrm{H}_{19} \mathrm{NO}_{3} \mathrm{~S}\right.$; Sigma-Aldrich, St. Louis, MO) were used as buffer reagents to maintain the $\mathrm{pH} 4$, 7, and 10, respectively.

Low-density polyethylene bottles (Nalge Nunc, Rochester, NY), perfluoroalkoxy tubes and micropipette tips (Nichiryo, Tokyo, Japan) were used throughout the experiments, and cleaned according to the procedure described by Hasegawa et al. (2011).

\subsection{Instrumentation}

Inductively coupled plasma optical emission spectrometer (ICP-OES) (iCAP 6300; Thermo Fisher Scientific, Waltham, MA) was used for metal concentration measurements. The ICP-OES was composed of an EMT duo quartz torch, glass spray chamber and concentric glass nebulizer, and was operated at the following conditions: the radio frequency power at the torch was $1.15 \mathrm{~kW}$, the plasma gas flow was $12 \mathrm{~L} \mathrm{~min}^{-1}$, the auxiliary gas flow was $1 \mathrm{~L} \mathrm{~min}^{-1}$, the nebulizer gas flow was $0.5 \mathrm{~L} \mathrm{~min}^{-1}$, and the integration time was $30 \mathrm{~s}$.

A microwave reaction system (Multiwave 3000; Anton Paar GmbH, Graz, Austria) was used for the digestion treatment of the soil samples. The system was equipped with 8-position rotor and hydraulic pressurized sensing system for all vessels. The vessels support controlled pressure of 6 $\mathrm{MPa}$, maximum operating pressure of $12 \mathrm{MPa}$ and highest temperature of $2600^{\circ} \mathrm{C}$.

Arium Pro water purification system from Sartorius Stedim Biotech GmbH (Göttingen, Germany) was used to produce the ultrapure water (resistivity $>18.2 \mathrm{M} \Omega \mathrm{cm}$ ). 


\subsection{Methods}

\subsubsection{Extraction of toxic metals from the contaminated soil using chelants}

The organic-rich metal-contaminated soil sample was treated batch-wise with EDTA, EDDS, IDSA, MGDA, GLDA and HIDS solutions $(0.05 \mathrm{M})$ at a ratio of 1:10 (w/v). The extraction protocol recommended for the recovery of EDTA-extractable fraction from BCR-700 by the EC-JRC-IRMM (Rauret et al., 2001) was followed, and conducted at $\mathrm{pH} \mathrm{4,} \mathrm{7,} \mathrm{and} \mathrm{10.} \mathrm{An} \mathrm{end-over-end} \mathrm{shaker} \mathrm{was}$ used for shaking the soil-chelant solution mixture for $1 \mathrm{~h}$ at about $30 \mathrm{rpm}$ at $20 \pm 4{ }^{\circ} \mathrm{C}$. The extracts were immediately separated from the solid phase by centrifugation for $10 \mathrm{~min}$ at $3000 \mathrm{rpm}$, and passing through the cellulose membrane filters of $0.45 \mu \mathrm{m}$ pore size (Advantec, Tokyo, Japan). The filtrates were stored at $4{ }^{\circ} \mathrm{C}$ until ICP-OES analysis. Before the treatment, the bottle containing the soil sample was manually shaken for $5 \mathrm{~min}$ to re-homogenize the content. For each batch of extractions, correction for dry mass was performed on separate portions of $1 \mathrm{~g}$ of soil taken at the same time from the same bottle by drying in an oven at $105 \pm 2{ }^{\circ} \mathrm{C}$ for $2-3 \mathrm{~h}$.

Experimental results obtained for EDTA extractable fraction at $\mathrm{pH} 7$ were compared with the certified reference values for BCR 700 (Table 2). The coefficients of variation were in the range of 2.6-8.4\%, which indicate good operative performance of the applied washing procedure.

Triplicate extractions were employed with and without the chelant solutions to estimate the reproducibility of the consequences with same circumstances.

\subsubsection{Distribution of toxic metals in the contaminated soil before and after chelant extraction}

Selective sequential extraction (SSE) procedure has been carried out to determine the mobility and dissemination of toxic metals in the organic-rich contaminated soil sample before and after the treatment with the chelants. The employed SSE scheme was developed by the Standard Measurements and Testing Programme (formerly BCR) of the European Community, and operationally defined the metal distribution in the contaminated soil into - (a) exchangeable, water and acid-soluble, (b) reducible, (c) oxidisable, and (d) residual fractions. The working protocol of the SSE scheme is described elsewhere (Rauret et al., 1999; Abollino et al., 2006).

\subsubsection{Microwave assisted digestion of the contaminated soil before and after chelant extraction}

Three types of soil samples were subjected to microwave assisted digestion: (a) raw soil - to 
determine the total metal content, (b) residue from the SSE treatment - before chelant extraction, (c) residue from SSE treatment - after chelant extraction. A $1 \mathrm{~g}$ of soil sample was placed into the precleaned PTFE vessels of the microwave reaction system and a mixture of $60 \% \mathrm{HNO}_{3}(3 \mathrm{~mL})$ and $36 \% \mathrm{HCl}(9 \mathrm{~mL})$ was added to it. Optimized operating conditions for the digestion were chosen according to the manufacturer recommendations and past studies on microwave assisted digestion optimization (Nieuwenhuize et al., 1991; Nemati et al., 2010), which were as follows: $P_{\max }=1000$ $\mathrm{W}$; ramp time $=6 \mathrm{~min}$; heating time at the maximum temperature $=20 \mathrm{~min}$; vent time $=25 \mathrm{~min}$. After finishing the instrumental procedure, the mixtures were filtered through $0.45 \mu \mathrm{m}$ pore sized cellulose membrane filters. The filtrate was then evaporated on a hot plate at $60{ }^{\circ} \mathrm{C}$ to reduce the volume to a few milliliters. All solutions were diluted to $100 \mathrm{~mL}$ with ultrapure water and stored at $4{ }^{\circ} \mathrm{C}$ until further analysis. A blank was treated with the same as the samples.

\subsubsection{Protonation constants of chelants and stability constants of the metal-chelant complexes}

The protonation constants and metal-chelant stability constants for EDTA, EDDS, IDSA and MGDA were used from the NIST database for critically selected stability constants of metal complexes (Martell et al., 2004). The same constants for GLDA and HIDS were calculated from the experimental potentiometric data using the HYPERQUAD 2008 program (Gans et al., 1996), and described in detail elsewhere (Begum et al., 2012).

\subsection{Results and Discussion}

\subsection{Total content and solid phase speciation of the metals in the contaminated soil}

Microwave assisted aqua regia digestion showed that the organic-rich soil sample, BCR 700, was amended with a high amount of toxic ions (Table 3). Based on the dry mass, the concentrations (mg $\mathrm{kg}^{-1}$ ) of the divalent metal ions are $\mathrm{Cd}$ (132), $\mathrm{Cu}$ (169), $\mathrm{Ni}(373), \mathrm{Pb}(288)$, and $\mathrm{Zn}$ (1584).

The total metal content represents the cumulative concentrations in the entire mineral structure of the soil solid that is digested. The estimate of metal leachability from soils is often misleading as it is assumed that the release continues until the total content has been depleted. However, the modes of metal retention within the soil have a deciding influence on the release of metals from contaminated soil (Barona et al., 2001). A series of extraction processes using gradually aggressive extractants can help us to operationally determine the nature of the metal fixation on the soil particles as well as the 
accurate quantification of the 'leachable' metal content (Tessier et al., 1979; Maiz et al., 2000; Ph, 2002). Solid phase speciation of the target ecotoxic ions in the organic-rich soil sample was operationally estimated by the SSE procedure, and a significant variation in the corresponding distributions in various fractions was observed (Table 3). The $\mathrm{Cd}$ and $\mathrm{Zn}$ were significantly partitioned into the 'exchangeable, water and acid-soluble' and the 'reducible' fraction. A substantial fraction $(39 \%)$ of the total Ni-content was retained in the residual fraction of the soil, i.e. strongly confined, and also predominantly partitioned to the 'reducible' fraction of the soil. The $\mathrm{Cu}$ and $\mathrm{Pb}$ were mostly attached to the 'reducible' fraction $(>70 \%$ of the total content). The potential mobility character as indicated by the concentrations of the studied metal ions in the 'exchangeable, water and acid-soluble' fraction followed the sequence $\mathrm{Cd} \approx \mathrm{Zn}>\mathrm{Ni}>\mathrm{Cu}>\mathrm{Pb}$.

\subsection{Washing treatment of the contaminated soils with chelants}

\subsubsection{Effect of $p H$}

The metal extraction efficiencies of the ultrapure water, EDTA and the biodegradable APCs at $\mathrm{pH} 4,7$, and 10 are shown in Fig. 1. In the absence of chelants, less than $7 \%$ extraction was achieved at $\mathrm{pH} 4$ while it was below $1.3 \%$ at $\mathrm{pH} 7$ and 10 . Such considerably low extraction efficiencies correspond to the negligible amount of the water-soluble fractions. Increased extraction efficiencies in the presence of chelants in solution with varying range of affectivity at different $\mathrm{pH}$ was observed. At $\mathrm{pH} 4$, different biodegradable chelants able to extract at least half of the total contents $(\%)$ of $\mathrm{Cd}$ (GLDA: 84, MGDA: 81, IDSA: 59, EDDS: 52), Cu (GLDA: 94, IDSA: 93, MGDA: 89, EDDS: 84, HIDS: 79), $\mathrm{Pb}$ (GLDA: 54) and Zn (GLDA: 62, MGDA: 60, IDSA: 55). The Ni extraction efficiencies (\%) with the biodegradable chelants remain in the range of 24-39 and were at the following order: GLDA $>$ MGDA $>$ IDSA $>$ HIDS $>$ EDDS. GLDA performed better than EDTA for the extraction of Ni (GLDA: 39\%, EDTA: 33\%) while both GLDA and IDSA showed superior extraction performance for $\mathrm{Cu}$ (GLDA: 94\%, IDSA: 93\%, EDTA: 91\%) at pH 4. A comparable extraction performance can be noted for Zn (EDTA: 63\%, GLDA: 62\%).

A metal extraction efficiencies (\%) at $\mathrm{pH} 7$ were in the following orders: Cd - GLDA (62) > MGDA (49) > HIDS (39) > EDDS (36) > IDSA (35); Cu - GLDA (44) > HIDS (39) > EDDS (37) > IDSA (36) > MGDA (35); Ni - GLDA (18) > HIDS (16) > EDDS (14) > IDSA (14) > MGDA (13); 
$\mathrm{Pb}-\mathrm{GLDA}(17)>\operatorname{IDA}(11)>\operatorname{MGDA}(10)>\operatorname{EDDS}(9)>\operatorname{HIDS}(5)$ and $\mathrm{Zn}-$ GLDA (32) $>$ HIDS $(25)>$ MGDA (25) $>$ EDDS (23) $>$ IDSA (23). Hence, the order of metal ion selectivity for the washing treatment with GLDA and MGDA was $\mathrm{Cd}>\mathrm{Cu}>\mathrm{Zn}>\mathrm{Ni}>\mathrm{Pb}$, with EDDS and IDSA was $\mathrm{Cu}>\mathrm{Cd}>\mathrm{Zn}>\mathrm{Ni}>\mathrm{Pb}$, and with HIDS was $\mathrm{Cd} \approx \mathrm{Cu}>\mathrm{Zn}>\mathrm{Ni}>\mathrm{Pb}$. GLDA showed higher efficiency of extraction at pH 7 than EDTA for Cd (GLDA: 62\%, EDTA: 59\%). A comparable Niextraction performance was observed with GLDA (18\%), HIDS (16\%) and EDTA (16\%).

The ranges of extraction efficiencies (\%) for different metal ions with the biodegradable chelants at $\mathrm{pH} 10$ are as follows: $\mathrm{Cd}-42-62(\mathrm{GLDA}>\mathrm{MGDA}>\mathrm{EDDS}>\mathrm{IDSA}>\mathrm{HIDS}) ; \mathrm{Cu}-46-67$ $($ EDDS $>$ MGDA $>$ IDSA $>$ GLDA $>$ HIDS) Ni $-15-21($ IDSA $>$ GLDA $>$ MGDA $>$ EDDS $>$ HIDS); $\mathrm{Pb}-8-22($ EDDS > MGDA > GLDA > HIDS > IDSA $) ; \mathrm{Zn}-22-30($ GLDA $>$ MGDA $>$ EDDS $>$ IDSA $>$ HIDS). None of the biodegradable chelants performed better than EDTA at pH 10.

Solution $\mathrm{pH}$ is expected to affect the chelant capability of metal extraction by controlling the aqueous metal species concentration, solubility of the chelants, sorption or desorption and ionexchange behavior of the metal ions, and re-adsorption mechanisms of the newly formed metalchelant complexes (Lim et al., 2004; Polettini et al., 2007). The performances of the chelants in the acidic ( $\mathrm{pH} 4)$, neutral $(\mathrm{pH} 7)$ and alkaline ( $\mathrm{pH}$ 10) conditions can be summarized as follows: (a) the extraction efficiencies were highest in the acidic conditions; (b) the efficiencies were decreased to a certain extent at neutral conditions compared to that of the acidic; (c) the extraction efficiencies at the alkaline environment were rather higher than that of the neutral and, except for the metal-chelant systems containing $\mathrm{Cu}$, the efficiencies were somewhat comparable.

At the acidic condition, chelants interact with the metal constituents of the contaminated soil leading to the simultaneous release of retained ions and an exchange of the $\mathrm{H}^{+}$with the absorbed metal ions via the protonation of surface functional group on soil solids (Stumm, 1992; Lim et al., 2004). Furthermore, at $\mathrm{pH}<5$, carbonates are completely soluble, whereby carbonate-bound metals become easily accessible for the complexation with the chelants (Vandevivere et al., 2001). Therefore, a higher efficiency of metal extraction is likely at $\mathrm{pH} 4$. The solubility of oxides and other solid phases decreases at the neutral conditions because of the formation of metal hydroxy complexes, and resulted in comparatively lower extraction abilities (Elliott and Brown, 1989). At alkaline conditions, the concentration of the reactive species $\mathrm{L}^{\mathrm{n}-}$ increases as it becomes 
deprotonated leading to the formation of soluble coordination compounds of the organic chelants at a efficiency greater than before (Fischer and Bipp, 2002).

The general trend is that the extraction efficiency obtained at $\mathrm{pH} 10$ is either lower or comparable than that obtained at $\mathrm{pH}$ 4. However, for the metal-chelant system containing $\mathrm{Pb}$ and EDDS, the efficiency of extraction at $\mathrm{pH} 10$ was significantly increased compared to that of $\mathrm{pH} 4$. Such occurrence may be attributable to the displacement of $\mathrm{Pb}$ from the EDDS complex followed by re-sorption through the direct absorption of $\mathrm{Pb}$-EDDS complex or exchange of ions with other metals in the soils, e.g. sorbed $\mathrm{Cu}$ on surface, Fe-oxides and Al-oxides/aluminosilicates (Tandy et al., 2004; Hauser et al., 2005).

Among the biodegradable APCs, GLDA demonstrated enhanced extraction efficiency than the other options at the acidic and neutral conditions for all the metals $(\mathrm{Cd}, \mathrm{Cu}, \mathrm{Ni}, \mathrm{Pb}$, and $\mathrm{Zn})$. At the alkaline conditions, GLDA was the superior option for the extraction of $\mathrm{Cd}, \mathrm{Ni}$, and $\mathrm{Zn}$ while EDDS and MGDA were better than GLDA for $\mathrm{Cu}$ and $\mathrm{Pb}$ extraction. HIDS is the least efficient of the biodegradable APCs at $\mathrm{pH} 4$ and 10, while it was among the first three of the extractant options at $\mathrm{pH} 7$.

\subsubsection{Effect of metal-chelant stability constants}

Chelants can interact with metals to form soluble metal-chelant complexes, and keep them in solution. The equilibrium speciation in a metal-chelant system is controlled by the concentrations of all metals and chelants and the stability constants of all complexes (Nowack, 2002). Stability of the metal-chelant complexes in solution is considered as a key issue for the consideration of a chelant in the chelant-based waste treatment processes. A number of factors, such as, oxidation state and coordination number of the metal ion, and the electronic structure and character of the chelant, determine the nature of the bond between the metal and chelant that may vary from electrostatic to covalent (Bell, 1977). The stability of the metal-chelant complexes followed different sequences: (a) EDTA: $\log K_{\mathrm{CuL}}>\log K_{\mathrm{NiL}}>\log K_{\mathrm{PbL}}>\log K_{\mathrm{ZnL}} \sim \log K_{\mathrm{CdL}}$; (b) EDDS and IDSA: $\log K_{\mathrm{CuL}}>\log K_{\mathrm{NiL}}>$ $\log K_{\mathrm{ZnL}}>\log K_{\mathrm{PbL}}>\log K_{\mathrm{CdL}}$; (c) MGDA: $\log K_{\mathrm{CuL}}>\log K_{\mathrm{PbL}}>\log K_{\mathrm{NiL}}>\log K_{\mathrm{ZnL}}>\log K_{\mathrm{CdL}}$; (d) GLDA and HIDS: $\log K_{\mathrm{CuL}}>\log K_{\mathrm{NiL}}>\log K_{\mathrm{PbL}}>\log K_{\mathrm{ZnL}}>\log K_{\mathrm{CdL}}$ (Table 1). The chelant complexes with $\mathrm{Cu}$ possess the higher stability in solution and the $\mathrm{Cd}$ complexes have the lower, while there is no uniform pattern for the other ions. 
The relative strength of the actual metal-chelant species present in the aqueous systems at different equilibrium conditions is measured by the conditional stability constant, which is primarily dependent on the $\mathrm{H}^{+}$ion activity in the solution (Polettini et al., 2007). Conditional stability constant is defined considering the effects of side reactions that may occur during the complexation of chelant with metal ions such as, the effects of chelant protonation and of hydrolysis that prevails when a metal ion is in solution (van Tonder et al., 2002). Figure 2 shows the change in conditional stability constants of various metal-chelant complexes in terms of the solution $\mathrm{pH}$ as calculated with the aid of the computer program HySS2009 (Alderighi et al., 1999) using the values mentioned in Table 1. The values of $\log K_{\mathrm{ML}}^{\prime}>6$ are considered as the suitable complexation range for practical use, and on that scale, the biodegradable chelants are not commonly appropriate for the separation of the target metal ions at the $\mathrm{pH}<5$ (exception: $\mathrm{Cu}$ with all the chelants, and $\mathrm{Ni}$ with EDDS and GLDA) (Fig. 2). Therefore, the higher metal extraction efficiency observed at $\mathrm{pH} 4$ with the biodegradable chelants cannot be related with the stability constants of the metal-chelant complexes in the solution.

The comparative selectivity of different chelants towards the ecotoxic metal ions, sorted in the order of largest to smallest, with the change in the conditional stability constants $\left(\log K^{\prime}{ }_{\mathrm{ML}}\right)$ of the metal-chelant complexes at $\mathrm{pH} 7$ and 10 are shown in Fig. 3. The observed selectivity order for the chelants under study for the target metals based on the values of the conditional stability constant for the different metal-chelant complexes did not yield any consistent results. The observed behavior can be attributed to the other related phenomena, such as, formation efficiency of the soluble dominant species in solution, solid phase precipitation of the metal ions, re-sorption of the metalchelant complexes in the active surface sites of the solid matrix, etc. Furthermore, coordination reactions of metal ions with chelants containing multiple bonding groups are often kinetically hindered (Nowack, 2002), and the varying extent of kinetic hindrance may take priority over the general extraction order preferences.

A general proportionate relationship can be assumed if we compare the experimental extraction data for individual chelant for each of the metals with that of the conditional stability constant values (Figs. 1 and 2). Some major exceptions should be noted, such as lower extraction efficiency of $\mathrm{Pb}$ IDSA complexes at $\mathrm{pH} 10$, substandard extraction efficiency of EDDS compared to the other biodegradable options at different $\mathrm{pH}$ environments, and unpredicted extraction performance of 
GLDA.

Lower $\mathrm{Pb}$ extraction efficiency with IDSA has been observed at $\mathrm{pH} \mathrm{10,} \mathrm{which} \mathrm{is} \mathrm{opposite} \mathrm{to} \mathrm{the}$ general trend. In the $\mathrm{Pb}$-IDSA system, the species $\mathrm{Pb}(\mathrm{IDSA})_{2}{ }^{6-}$ predominates at $\mathrm{pH} 10$ and behaves as a hexavalent anion. The anionic form is free to move in soil solution or to be absorbed onto solid surfaces. Therefore, a decrease in the extraction efficiency could be resulted due to the competitive mobilization of other coexisting metal ions in the soil matrix (e.g. $\mathrm{Ca}, \mathrm{Mn}, \mathrm{Fe}, \mathrm{Al}$, etc.) towards the chelant or absorption of the Pb-IDSA complex to the solid matrix (Steele and Pichtel, 1998).

The metal extraction efficiency with EDDS compared to the other biodegradable chelants was not that superior as assumed based on the conditional stability constant values. The speciation of the dissociated species of the EDDS in solution shows the lower formation efficiency of the dominant species $\left(\operatorname{HEDDS}^{3-} ; 59 \%\right.$ ), and can be a reason for such behavior of EDDS. Furthermore, in the metal-EDDS system, a rapid change in the concentration of trivalent Fe with the change in $\mathrm{pH}$ than other divalent metals resulted in iron interference and decreased efficiency of extraction (Elliott and Brown, 1989; Vandevivere et al., 2001).

A superior metal extraction performance with GLDA than the other biodegradable chelants having higher metal-chelant stability constants was observed. GLDA generates aqueous acid in the soluble state, which remain in solution over a wide range of concentration than the other chelants and create a more acidic environment favoring the higher efficiency of extraction (Wolf et al., 2010).

\subsubsection{Effect of potentially interfering cations}

The behavior of the major potentially interfering cations (e.g. $\mathrm{Al}, \mathrm{Ca}, \mathrm{Fe}, \mathrm{Mg}$, and $\mathrm{Mn}$ ) was considered to explain the extraction performance using at a ratio of 1:10 (w/v) metal and chelant. The organic-rich soil sample, BCR 700, was subjected to microwave assisted aqua regia digestion and SSE treatment to determine the total concentration and solid phase distribution of the target nontoxic cations. The total concentrations of $\mathrm{Al}, \mathrm{Ca}, \mathrm{Fe}, \mathrm{Mg}$, and $\mathrm{Mn}$ ions in the soil sample were, respectively, $25723 \pm 14,8365 \pm 19,35804 \pm 136,3355 \pm 38$ and $1144 \pm 12 \mathrm{mg} \mathrm{kg}^{-1}$. The SSE data showed that a considerable amount of the total metal content was immobilized in the residual fraction of the soil sample: $\mathrm{Al}, 90 \% ; \mathrm{Ca}, 52 \% ; \mathrm{Fe}, 73 \% ; \mathrm{Mg}, 71 \%$ and $\mathrm{Mn}, 24 \%$, which is theoretically difficult to get to via the extraction treatment. The percentages of exchangeable, water and acid-soluble $\mathrm{Al}$ and $\mathrm{Fe}$ were extremely low (1\% and $0.1 \%$, respectively), in comparison with the 
other elements, probably because of the strong tendency of these metals to form oxides and hydroxides (Abollino et al., 2006). The proportion of the metals released in the reducible fraction (Al: 9\%; Fe: 29\%) possibly derives from the dissolution of amorphous and, to a lesser extent, of crystalline oxides (Li et al., 1995; Zhang et al., 1998). Manganese was present at low levels in the exchangeable, water and acid-soluble (13\%) and organic bound (3\%) fractions, whereas it was extensively released (61\%) into the reducible (i.e. carbonate, iron or manganese oxides bound fraction), reflecting the dissolution of manganese oxides (Maiz et al., 2000). A considerable amount of $\mathrm{Ca}$ and $\mathrm{Mg}$ is partitioned in the fraction $1(\mathrm{Ca}: 25 \%$; $\mathrm{Mg}: 23 \%)$ and fraction $2(\mathrm{Ca}: 17 \%$; $\mathrm{Mg}$ : $12 \%$ ), and amenable for extraction with chelants. Concerning the behavior of major cations, in general $\mathrm{Ca}$ followed by $\mathrm{Mg}$ were strong competitors in chelant-assisted extraction of toxic metals from soils (Polettini et al., 2007). However, the competition between these two metals and the target pollutant metals for the available chelant is particularly important for the low chelant: metal ratio of 1. According to the speciation calculations and geochemical modeling results, most of the chelant remained in the free form in solution at a chelant: metal ratio of 10 (Tandy et al., 2004; Polettini et al., 2007). Hence, there was always enough free chelant available for further extraction of the target metals, and to avoid the competition effect from the co-existing interfering ions.

\subsection{Effect of chelant washing on the distribution of metals in soil}

The reactivity and behavior of the metals in the soil sample towards the extracting solutions depend on the partitioning of metals within the soil, and can be used to explain the varied extraction efficiencies for different metals (Barona et al., 2001). The $\mathrm{Cd}, \mathrm{Cu}, \mathrm{Ni}, \mathrm{Pb}$, and $\mathrm{Zn}$ speciation in the solid phase of soil was operationally defined with SSE, and comparative scenarios of SSE results before and after treatment with EDTA and the biodegradable chelants (EDDS, IDSA, MGDA, GLDA and HIDS) are shown in Fig. 4. The sum of the metal concentrations obtained for each soil solid fractions were compared with the total metal concentrations obtained from microwave assisted digestion of the raw soil (Table 3). The evaluation showed higher extraction results with SSE than that for the one-step digestion treatment while the differences were not greater than $4.5 \%$. The SSE results indicate that $99 \%, 88 \%, 62 \%, 89 \%$, and $91 \%$ of the total $\mathrm{Cd}, \mathrm{Cu}, \mathrm{Ni}, \mathrm{Pb}$, and $\mathrm{Zn}$ contents, respectively, are non-detrital. The non-detrital metals, i.e. exchangeable, water and acid-soluble (fraction 1), reducible (fraction 2) and oxidisable (fraction 3) fractions, are those not incorporated 
within the crystalline lattice of the soil, i.e. not associated with the residual fraction and are considered amenable to soil extraction (Steele and Pichtel, 1998). However, the release of metals from the contaminated soil depends not only on the solid phase incorporation of the metals, but also on the extraction conditions, e.g. concentration of the extractants, $\mathrm{pH}$ conditions, co-existing competing ion concentrations and comparative selectivity of the chelants towards the metal ions (Peters, 1999; Barona et al., 2001; Tandy et al., 2004).

The comparative SSE results showed that a significant reduction in the metal contents of fraction 1 (in the range of 50-100\%) was occurred after the treatment with the chelants except that for $\mathrm{Cu}$ with EDDS and IDSA (efficiency of reduction was $11 \%$ and $32 \%$, respectively). The $\mathrm{Pb}$ content became zero except for the system with EDDS (efficiency of reduction: 80\%), which may be due to its low content $\left(7.9 \mathrm{mg} \mathrm{kg}^{-1}\right)$ in the corresponding soil fraction.

Metal ions partitioned in the fraction 2 (reducible content) was also reduced after the chelant treatment of the contaminated soil except that for Zn with the EDDS, IDSA, MGDA, GLDA and HIDS showing an increase in the metal concentrations of the corresponding fraction. The increase in the reducible $\mathrm{Zn}$ amounts after the treatment with the biodegradable chelants may be attributed to the competitive behavior of the $\mathrm{H}_{3} \mathrm{O}^{+}$for adsorption sites, and to the fact that this chelants may form comparatively more stable water-soluble complexes, which are weakly adsorbed to the soil particles ( $\mathrm{Yu}$ and Klarup, 1994). The interaction between the $\mathrm{Ni}$ content in the fraction 2 and the biodegradable chelants were low as indicated by the reduction efficiency of below $11 \%$, which may be due to the stronger affinity of the Ni to that particular fraction of the soil phase than that of the other metals.

The metal content in the fraction 3 was increased after the treatment with the chelants in most of the cases. There was a decrease in the concentration of Pb with GLDA and EDTA while the concentration of Ni remains unaffected after the treatment with GLDA. The chelant treatment also had an effect on the soil metal content in the residual fraction showing both increasing and decreasing trend. An increase in the metal content was observed for Cd with EDTA and EDDS, $\mathrm{Cu}$ with all the chelants except GLDA, $\mathrm{Ni}$ and $\mathrm{Zn}$ with EDTA, and $\mathrm{Pb}$ with the all the chelants. The exceptions, as mentioned, showed the decreasing magnitude in the metal content of the corresponding fraction after the chelant treatment. Fraction 3 represents the metal ions bound to the 
organic matter, humic acids and sulfides which are the less labile forms, while the residual fraction (fraction 4) of the metal ions in the contaminated soil was also very persistent and unlikely to be extracted easily. The increase in the associated amounts of metals in the less mobile fractions may be caused by both the present of residual chelant in the material after treatment, and the incapability of the SSE process applied to differentiate between the oxidisable constituents of diverse nature (Polettini et al., 2007). Organic chelants are capable to induce mineral dissolution via surface complexation with mineral metals (Stumm, 1992), and that probably cause the release of metal ions from the theoretically immobilized fractions of the contaminated soil (Sun et al., 2001; Lim et al., 2004).

\subsection{Conclusions}

Extractive-decontamination of the toxic metals $(\mathrm{Cd}, \mathrm{Cu}, \mathrm{Ni}, \mathrm{Pb}$, and $\mathrm{Zn})$ from the organic-rich contaminated soil using biodegradable chelants (EDDS, MGDA, IDSA, GLDA, and HIDS) was evaluated. The aim was to recommend a potential eco-friendly alternative of EDTA, which is under scrutiny for its prolonged environmental persistence and related negative consequences. Comparative orders of toxic metal removals (\%) from organic-rich soil achieved with the various biodegradable chelants at $\mathrm{pH} 7$ are as follows: EDDS and IDSA $(\mathrm{Cu}>\mathrm{Cd}>\mathrm{Zn}>\mathrm{Ni}>\mathrm{Pb}), \mathrm{MGDA}$ and GLDA $(\mathrm{Cd}>\mathrm{Cu}>\mathrm{Zn}>\mathrm{Ni}>\mathrm{Pb})$, and HIDS $(\mathrm{Cd} \approx \mathrm{Cu}>\mathrm{Zn}>\mathrm{Ni}>\mathrm{Pb})$. The metal speciation calculations were used to predict the selectivity behavior of chelants at different $\mathrm{pH}$ towards the toxic ions, and no consistent pattern was observed. Sequential extraction results indicate that the higher the accumulation in the non-detrital fraction, the greater is the potential leachability from the soil matrix. However, the application of chelants also releases the important nutrient minerals from the soil, and the enhanced metal leachability due to the chelants requires careful control primarily by the adjustment of $\mathrm{pH}$. The relative efficiencies among the biodegradable APCs for the extraction of the target toxic metals at $\mathrm{pH} 7$ followed the order: Cd (GLDA $>$ MGDA $>$ HIDS $>$ EDDS $\approx$ IDSA), $\mathrm{Cu}($ GLDA $>$ HIDS $>$ EDDS $>$ IDSA $>$ MGDA $)$, Ni $($ GLDA $>$ HIDS $>$ EDDS $>$ IDSA $>$ MGDA $)$, $\mathrm{Pb}($ GLDA $>$ IDSA $\approx$ MGDA $>$ EDDS $>$ HIDS $)$, and $\mathrm{Zn}($ GLDA $>$ HIDS $\approx$ MGDA $>$ EDDS $>$ IDSA). At $\mathrm{pH} 10$, the extraction ability of EDDS, IDSA and MGDA were greater for Cu, and EDDS and MGDA were greater for $\mathrm{Pb}$ than that of GLDA. Hence, GLDA is the better eco-suitable 
alternative for ex situ soil washing treatment among the investigated options at neutral conditions while the efficiency is sometimes altered at alkaline environment.

\section{Acknowledgements}

This research was partially supported by the Grants-in-Aid for Scientific Research (K22042) from the Ministry of the Environment, Japan. Additionally, the authors (ZAB and IMMR) wish to thank Mr. Rauful Alam (Department of Organic Chemistry, Stockholm University, Sweden) for his useful support in collecting the literatures. 


\section{References}

Abollino, O., Giacomino, A., Malandrino, M., Mentasti, E., Aceto, M., Barberis, R., 2006. Assessment of metal availability in a contaminated soil by sequential extraction. Water Air Soil Poll. 173, 315-338.

Abumaizar, R., Khan, L.I., 1996. Laboratory investigation of heavy metal removal by soil washing. J. Air Waste Ma. 46, 765-768.

Alderighi, L., Gans, P., Ienco, A., Peters, D., Sabatini, A., Vacca, A., 1999. Hyperquad simulation and speciation (HySS): A utility program for the investigation of equilibria involving soluble and partially soluble species. Coordin. Chem. Rev. 184, 311-318.

Barona, A., Aranguiz, I., Elías, A., 2001. Metal associations in soils before and after EDTA extractive decontamination: implications for the effectiveness of further clean-up procedures. Environ. Pollut. 113, 79-85.

Begum, Z.A., Rahman, I.M.M., Tate, Y., Egawa, Y., Maki, T., Hasegawa, H., 2012. Formation and stability of binary complexes of divalent ecotoxic ions $(\mathrm{Ni}, \mathrm{Cu}, \mathrm{Zn}, \mathrm{Cd}, \mathrm{Pb})$ with biodegradable aminopolycarboxylate chelants (DL-2-(2-carboxymethyl)nitrilotriacetic acid, GLDA, and 3-hydroxy-2,2'-iminodisuccinic acid, HIDS) in aqueous solutions. J. Solution Chem. (In Press).

Bell, C.F., 1977. Principles and Applications of Metal Chelation. Clarendon Press, Oxford.

Dermont, G., Bergeron, M., Mercier, G., Richer-Laflèche, M., 2008. Soil washing for metal removal: A review of physical/chemical technologies and field applications. J. Hazard. Mater. $152,1-31$

Ebina, Y., Okada, S., Hamazaki, S., Ogino, F., Li, J.L., Midorikawa, O., 1986. Nephrotoxicity and renal cell carcinoma after use of iron- and aluminum-nitrilotriacetate complexes in rats. J. Natl. Cancer I. 76, 107-113.

Egli, T., 2001. Biodegradation of metal-complexing aminopolycarboxylic acids. J. Biosci. Bioeng. 92, 89-97.

Elliott, H.A., Brown, G.A., 1989. Comparative evaluation of NTA and EDTA for extractive decontamination of Pb-polluted soils. Water Air Soil Poll. 45, 361-369.

Fischer, K., Bipp, H.P., 2002. Removal of heavy metals from soil components and soils by natural chelating agents. Part II. Soil extraction by sugar acids. Water Air Soil Poll. 138, 271-288.

Gans, P., Sabatini, A., Vacca, A., 1996. Investigation of equilibria in solution. Determination of equilibrium constants with the HYPERQUAD suite of programs. Talanta 43, 1739-1753.

Hasegawa, H., Rahman, I.M.M., Kinoshita, S., Maki, T., Furusho, Y., 2010. Non-destructive separation of metal ions from wastewater containing excess aminopolycarboxylate chelant in solution with an ion-selective immobilized macrocyclic material. Chemosphere 79, 193-198. 
Hasegawa, H., Rahman, I.M.M., Nakano, M., Begum, Z.A., Egawa, Y., Maki, T., Furusho, Y., Mizutani, S., 2011. Recovery of toxic metal ions from washing effluent containing excess aminopolycarboxylate chelant in solution. Water Res. 45, 4844-4854.

Hauser, L., Tandy, S., Schulin, R., Nowack, B., 2005. Column extraction of heavy metals from soils using the biodegradable chelating agent EDDS. Environ. Sci. Technol. 39, 6819-6824.

Leštan, D., Luo, C.L., Li, X.D., 2008. The use of chelating agents in the remediation of metalcontaminated soils: A review. Environ. Pollut. 153, 3-13.

Li, X., Coles, B.J., Ramsey, M.H., Thornton, I., 1995. Chemical partitioning of the new National Institute of Standards and Technology standard reference materials (SRM 2709-2711) by sequential extraction using inductively coupled plasma atomic emission spectrometry. Analyst 120, 1415-1419.

Lim, T.T., Tay, J.H., Wang, J.Y., 2004. Chelating-agent-enhanced heavy metal extraction from a contaminated acidic soil. J. Environ. Eng.-ASCE 130, 59-66.

Maiz, I., Arambarri, I., Garcia, R., Millán, E., 2000. Evaluation of heavy metal availability in polluted soils by two sequential extraction procedures using factor analysis. Environ. Pollut. $110,3-9$.

Martell, A.E., Smith, R.M., Motekaitis, R.J., 2004. NIST Standard Reference Database 46: NIST Critically Selected Stability Constants of Metal Complexes Database (Version 8.0 For Windows). Texas A\&M University, College Station, TX.

Nemati, K., Abu Bakar, N.K., Abas, M.R.B., Sobhanzadeh, E., Low, K.H., 2010. Comparative study on open system digestion and microwave assisted digestion methods for metal determination in shrimp sludge compost. J. Hazard. Mater. 182, 453-459.

Nieuwenhuize, J., Poley-Vos, C.H., van den Akker, A.H., van Delft, W., 1991. Comparison of microwave and conventional extraction techniques for the determination of metals in soil, sediment and sludge samples by atomic spectrometry. Analyst 116, 347-351.

Nowack, B., 2002. Environmental chemistry of aminopolycarboxylate chelating agents. Environ. Sci. Technol. 36, 4009-4016.

Peters, R.W., 1999. Chelant extraction of heavy metals from contaminated soils. J. Hazard. Mater. $66,151-210$.

Ph, Q., 2002. Operationally-defined extraction procedures for soil and sediment analysis. Part 3: New CRMs for trace-element extractable contents. Trac-Trend Anal. Chem. 21, 774-785.

Pichtel, J., Pichtel, T.M., 1997. Comparison of solvents for ex situ removal of chromium and lead from contaminated soil. Environ. Eng. Sci. 14, 97-104.

Polettini, A., Pomi, R., Rolle, E., 2007. The effect of operating variables on chelant-assisted remediation of contaminated dredged sediment. Chemosphere 66, 866-877. 
Pueyo, M., Rauret, G., Bacon, J.R., Gomez, A., Muntau, H., Quevauviller, P., F Lopez-Sanchez, J., 2001. A new organic-rich soil reference material certified for its EDTA- and acetic acidextractable contents of $\mathrm{Cd}, \mathrm{Cr}, \mathrm{Cu}, \mathrm{Ni}, \mathrm{Pb}$ and $\mathrm{Zn}$, following collaboratively tested and harmonised procedures. J. Environ. Monitor. 3, 238-242.

Rahman, I.M.M., Hossain, M.M., Begum, Z.A., Rahman, M.A., Hasegawa, H., 2010. Ecoenvironmental consequences associated with chelant-assisted phytoremediation of metalcontaminated soil. In: Golubev, I.A. (Ed.). Handbook of Phytoremediation. Nova Science Publishers, New York, pp. 709-722.

Rauret, G., F. Lopez-Sanchez, J., Sahuquillo, A., Rubio, R., Davidson, C., Ure, A., Quevauviller, P., 1999. Improvement of the BCR three step sequential extraction procedure prior to the certification of new sediment and soil reference materials. J. Environ. Monitor. 1, 57-61.

Rauret, G., Lopez-Sanchez, J.F., Bacon, J., Gomez, A., Muntau, H., Quevauviller, P., 2001. Certification of the Contents (Mass Fractions) of $\mathrm{Cd}, \mathrm{Cr}, \mathrm{Cu}, \mathrm{Ni}, \mathrm{Pb}$ and $\mathrm{Zn}$ in an OrganicRich Soil Following Harmonised EDTA and Acetic Acid Extraction Procedures: BCR-700. Directorate-General for Research, European Commission, Luxembourg.

Sillanpää, M., Oikari, A., 1996. Assessing the impact of complexation by EDTA and DTPA on heavy metal toxicity using microtox bioassay. Chemosphere 32, 1485-1497.

Steele, M.C., Pichtel, J., 1998. Ex-situ remediation of a metal-contaminated superfund soil using selective extractants. J. Environ. Eng.-ASCE 124, 639-645.

Stumm, W., 1992. Chemistry of the Solid Water Interface: Processes at the Mineral-Water and Particle-Water Interface in Natural Systems. Wiley, New York.

Sun, B., Zhao, F.J., Lombi, E., McGrath, S.P., 2001. Leaching of heavy metals from contaminated soils using EDTA. Environ. Pollut. 113, 111-120.

Tandy, S., Bossart, K., Mueller, R., Ritschel, J., Hauser, L., Schulin, R., Nowack, B., 2004. Extraction of heavy metals from soils using biodegradable chelating agents. Environ. Sci. Technol. 38, 937-944.

Tessier, A., Campbell, P.G.C., Bisson, M., 1979. Sequential extraction procedure for the speciation of particulate trace metals. Anal. Chem. 51, 844-851.

van Tonder, G.J., Cilliers, P.J., Meyer, E.H.O., Vegter, N.M., Klue, R., Izatt, S.R., Bruening, R.L., 2002. Cobalt and nickel removal from Zincor impure electrolyte by Molecular Recognition Technology (MRT) - pilot plant demonstration. J. S. Afr. I. Min. Metall. 102, 11-17.

Vandevivere, P., Hammes, F., Verstraete, W., Feijtel, T., Schowanek, D., 2001. Metal decontamination of soil, sediment, and sewage sludge by means of transition metal chelant [S,S]-EDDS. J. Environ. Eng.-ASCE 127, 802-811.

Wolf, C.A.D., Lepage, J.N., Bemelaar, J.H., 2010. Acidic Aqueous Solution Containing a Chelating 
Agent and the Use Thereof. United States Patent Application Publication. Akzo Nobel N.V., USA.

Yu, J., Klarup, D., 1994. Extraction kinetics of copper, zinc, iron, and manganese from contaminated sediment using disodium ethylenediaminetetraacetate. Water Air Soil Poll. 75, 205-225.

Zhang, L., Zhu, Z., Zhang, R., Zheng, C., Zhang, H., Qiu, Y., Zhao, J., 2008. Extraction of copper from sewage sludge using biodegradable chelant EDDS. J. Environ. Sci. 20, 970-974.

Zhang, T., Shan, X., Li, F., 1998. Comparison of two sequential extraction procedures for speciation analysis of metals in soils and plant availability. Commun. Soil Sci. Plan. 29, 1023-1034. 
1 Table 1: Chemical structure, acid dissociation constants $\left(\mathrm{p} K_{\mathrm{a}}\right)$ of the chelants, stability constants $2\left(\log K_{\mathrm{ML}}\right)$ of metal-chelant complexes, and initial speciation of chelant in the assay mixture (at $\left.\mathrm{pH} 7\right)$ 3 containing the chelant and metal ion (1:1 molar ratio)

4

\begin{tabular}{|c|c|c|c|c|c|c|c|c|}
\hline \multirow[t]{2}{*}{ APCs } & \multirow[t]{2}{*}{ Structure } & \multicolumn{4}{|l|}{$\mathrm{p} K_{\mathrm{a}}$} & \multirow[t]{2}{*}{ Metal } & \multirow[t]{2}{*}{$\log K_{\mathrm{ML}}$} & \multirow{2}{*}{$\begin{array}{l}\text { Speciation of chelant in the assay mixture } \\
(\% \text { of total chelant })^{\mathrm{d}}\end{array}$} \\
\hline & & $\mathrm{p} K_{\mathrm{a} 1}$ & $\mathrm{p} K_{\mathrm{a} 2}$ & $\mathrm{p} K_{\mathrm{a} 3}$ & $\mathrm{p} K_{\mathrm{a} 4}$ & & & \\
\hline \multirow[t]{6}{*}{ EDTA $^{\mathrm{a}}$} & \multirow[t]{6}{*}{ ноос } & \multirow[t]{6}{*}{2.00} & \multirow[t]{6}{*}{2.69} & \multirow[t]{6}{*}{6.13} & \multirow[t]{6}{*}{10.37} & - & - & $\operatorname{HEDTA}^{3-}(87.7), \mathrm{H}_{2}$ EDTA $^{2-}(12.0)$ \\
\hline & & & & & & $\mathrm{Cd}$ & 16.5 & CdEDTA $^{2-}(99.8)$ \\
\hline & & & & & & $\mathrm{Cu}$ & 18.78 & $\mathrm{CuEDTA}^{2-}(99.8)$ \\
\hline & & & & & & $\mathrm{Ni}$ & 18.4 & $\mathrm{NiEDTA}^{2-}(99.8)$ \\
\hline & & & & & & $\mathrm{Pb}$ & 18 & PbEDTA $^{2-}(99.8)$ \\
\hline & & & & & & $\mathrm{Zn}$ & 16.5 & ZnEDTA $^{2-}(99.8)$ \\
\hline \multirow{6}{*}{$\operatorname{EDDS}^{\mathrm{a}}$} & & \multirow[t]{6}{*}{2.95} & \multirow[t]{6}{*}{3.86} & \multirow[t]{6}{*}{6.84} & \multirow[t]{6}{*}{10.01} & - & - & $\operatorname{HEDDS}^{3-}(58.9), \mathrm{H}_{2} \operatorname{EDDS}^{2-}$ (41.1) \\
\hline & & & & & & $\mathrm{Cd}$ & $10.9^{b}$ & $\operatorname{CdEDDS}^{2-}(99.5)$ \\
\hline & & & & & & $\mathrm{Cu}$ & 18.36 & $\mathrm{CuEDDS}^{2-}(99.8)$ \\
\hline & & & & & & $\mathrm{Ni}$ & 16.7 & $\mathrm{NiEDDS}^{2-}(99.8)$ \\
\hline & & & & & & $\mathrm{Pb}$ & $12.7^{b}$ & $\operatorname{PbEDDS}^{2-}$ (92.7), PbHEDDS $^{-}$(7.3) \\
\hline & & & & & & $\mathrm{Zn}$ & $13.4^{b}$ & $\mathrm{ZnEDDS}^{2-}$ (66.8), $\mathrm{ZnHEDDS}^{-}$(33.2) \\
\hline \multirow[t]{6}{*}{ IDSA $^{\mathrm{a}}$} & & \multirow[t]{6}{*}{1.97} & \multirow[t]{6}{*}{3.24} & \multirow[t]{6}{*}{4.24} & \multirow[t]{6}{*}{10.00} & - & - & $\mathrm{HIDSA}^{3-}(99.5), \mathrm{H}_{2} \mathrm{IDSA}^{2-}(0.5)$ \\
\hline & & & & & & $\mathrm{Cd}$ & 8.33 & $\mathrm{CdIDSA}^{2-}$ (97.4), $\mathrm{CdHIDSA}^{-}(0.7)$ \\
\hline & & & & & & $\mathrm{Cu}$ & 12.69 & $\mathrm{CuIDSA}^{2-}(99.8)$ \\
\hline & & & & & & $\mathrm{Ni}$ & 11.68 & $\mathrm{NiIDSA}^{2-}(99.5), \mathrm{NiHIDSA}^{-}(0.5)$ \\
\hline & & & & & & $\mathrm{Pb}$ & 9.75 & $\mathrm{~Pb}(\operatorname{IDSA})^{6-}(63.7), \mathrm{PbIDSA}^{2-}(36.1)$ \\
\hline & & & & & & $\mathrm{Zn}$ & 9.88 & $\mathrm{ZnIDSA}^{2-}$ (99.3), ZnHIDSA ${ }^{-}(0.5)$ \\
\hline \multirow[t]{6}{*}{$\mathrm{MGDA}^{\mathrm{b}}$} & & \multirow[t]{6}{*}{1.5} & \multirow[t]{6}{*}{2.45} & \multirow[t]{6}{*}{10.43} & & - & - & $\mathrm{HMGDA}^{2-}(99.8)$ \\
\hline & & & & & & $\mathrm{Cd}$ & 10.61 & $\mathrm{CdMGDA}^{-}(99.8)$ \\
\hline & & & & & & $\mathrm{Cu}$ & 13.88 & $\mathrm{CuMGDA}^{-}(99.8)$ \\
\hline & & & & & & $\mathrm{Ni}$ & 11.99 & $\mathrm{NiMGDA}^{-}(99.8)$ \\
\hline & & & & & & $\mathrm{Pb}$ & 12.07 & $\mathrm{PbMGDA}^{-}(99.8)$ \\
\hline & & & & & & $\mathrm{Zn}$ & 10.98 & $\mathrm{ZnMGDA}^{-}$(99.8) \\
\hline GLDA $^{\mathrm{c}}$ & & 2.56 & 3.49 & 5.01 & 9.39 & - & - & $\operatorname{HGLDA}^{3-}(98.3), \mathrm{H}_{2} \mathrm{GLDA}^{2-}(1.4)$ \\
\hline & & & & & & $\mathrm{Cd}$ & 10.31 & $\mathrm{CdGLDA}^{2-}$ (99.3), $\mathrm{CdHGLDA}^{-}(0.7)$ \\
\hline & & & & & & $\mathrm{Cu}$ & 13.03 & $\mathrm{CuGLDA}^{2-}(99.5)$ \\
\hline & & & & & & $\mathrm{Ni}$ & 12.74 & $\operatorname{NiGLDA}^{2-}(99.5)$ \\
\hline & & & & & & $\mathrm{Pb}$ & 11.6 & $\mathrm{PbGLDA}^{2-}$ (99.3), $\mathrm{PbHGLDA}^{-}(0.7)$ \\
\hline & & & & & & $\mathrm{Zn}$ & 11.52 & $\mathrm{ZnGLDA}^{2-}$ (99.3), ZnHGLDA ${ }^{-}(0.7)$ \\
\hline $\mathrm{HIDS}^{\mathrm{c}}$ & & 2.14 & 3.08 & 4.07 & 9.61 & - & - & $\operatorname{HHIDS}^{3-}(99.5)$ \\
\hline & & & & & & $\mathrm{Cd}$ & 7.58 & $\mathrm{CdHIDS}^{2-}$ (91.4), $\mathrm{Cd}_{2} \mathrm{HIDS}$ (3.9) \\
\hline & & & & & & $\mathrm{Cu}$ & 12.58 & $\mathrm{CuHIDS}^{2-}$ (98.6), $\mathrm{Cu}(\mathrm{OH}) \mathrm{HIDS}^{3-}(1.4)$ \\
\hline & & & & & & $\mathrm{Ni}$ & 11.3 & $\mathrm{NiHIDS}^{2-}(99.5)$ \\
\hline & & & & & & $\mathrm{Pb}$ & 10.21 & $\mathrm{PbHIDS}^{2-}$ (99.3), $\mathrm{Pb}(\mathrm{OH}) \mathrm{HIDS}^{3-}$ (0.7) \\
\hline & & & & & & $\mathrm{Zn}$ & 9.76 & $\mathrm{ZnHIDS}^{2-}$ (98.6), Zn(OH)HIDS ${ }^{3-}(1.4)$ \\
\hline
\end{tabular}

'-' stands for 'no metal added'.

${ }^{\text {a }}$ At $25^{\circ} \mathrm{C}(\mu=0.1 \mathrm{M})$, (Martell et al., 2004).

${ }^{\mathrm{b}}$ At $20^{\circ} \mathrm{C}(\mu=0.1 \mathrm{M})$, (Martell et al., 2004).

${ }^{\mathrm{c}}$ At $25^{\circ} \mathrm{C}(\mu=0.1 \mathrm{M})$, (Begum et al., 2012).

${ }^{\mathrm{d}}$ Only the two most important chelant species are listed. When the \% formation of the dominant species is $>99.5$, other

10 species is not mentioned. Calculations were performed with the computer program HySS2009 (Alderighi et al., 1999). 
12 Table 2: Comparison of experimental and certified data for EDTA extractable fraction at $\mathrm{pH} 7$

13

\begin{tabular}{llllll}
\hline Element & Unit & Experimental value & Uncertainty & Certified value & Uncertainty \\
\hline $\mathrm{Cd}$ & $\mathrm{mg} \mathrm{kg}^{-1}$ & 77.1 & 1.3 & 65.2 & 3.5 \\
$\mathrm{Cu}$ & $\mathrm{mg} \mathrm{kg}^{-1}$ & 84.4 & 2.1 & 89.4 & 2.8 \\
$\mathrm{Ni}$ & $\mathrm{mg} \mathrm{kg}^{-1}$ & 59.6 & 1.3 & 53.2 & 2.8 \\
$\mathrm{~Pb}$ & $\mathrm{mg} \mathrm{kg}^{-1}$ & 108.5 & 4.9 & 103 & 5 \\
$\mathrm{Zn}$ & $\mathrm{mg} \mathrm{kg}^{-1}$ & 582.4 & 12.6 & 510 & 17 \\
\hline
\end{tabular}

14

15

16

17 
18 Table 3: Total concentrations and solid phase speciation of the toxic metals in the contaminated soil 19 sample

20

\begin{tabular}{llllll}
\hline Fractionation & $\mathrm{Cd}$ & $\mathrm{Cu}$ & $\mathrm{Ni}$ & $\mathrm{Pb}$ & $\mathrm{Zn}$ \\
\hline Total metal concentrations $\left(\mathrm{mg} \mathrm{kg}^{-1}\right)$ & $132 \pm 2$ & $169 \pm 4$ & $373 \pm 6$ & $288 \pm 3$ & $1584 \pm 22$ \\
Metal concentrations in the solid phase fractions $\left(\mathrm{mg} \mathrm{kg}^{-1}\right)$ & & & \\
Exchangeable, water and acid-soluble & $56.3 \pm 1.2$ & $19.4 \pm 0.1$ & $66.0 \pm 0.6$ & $7.9 \pm 1.1$ & $675.3 \pm 14.4$ \\
Reducible & $73.4 \pm 4.0$ & $118.3 \pm 0.8$ & $158.4 \pm 3.8$ & $238.1 \pm 4.3$ & $717.4 \pm 26.4$ \\
Oxidisable & $2.1 \pm 0.1$ & $16.4 \pm 0.3$ & $14.3 \pm 0.5$ & $17.0 \pm 6.3$ & $117.7 \pm 0.7$ \\
Residual & $1.8 \pm 0.3$ & $21.5 \pm 1.0$ & $143.9 \pm 0.7$ & $31.6 \pm 6.5$ & $145.4 \pm 5.0$
\end{tabular}

Recovery of total metal concentrations from the solid phase fractions (\%)

$\begin{array}{lllll}101.5 & 104.0 & 102.5 & 102.2 & 104.5\end{array}$



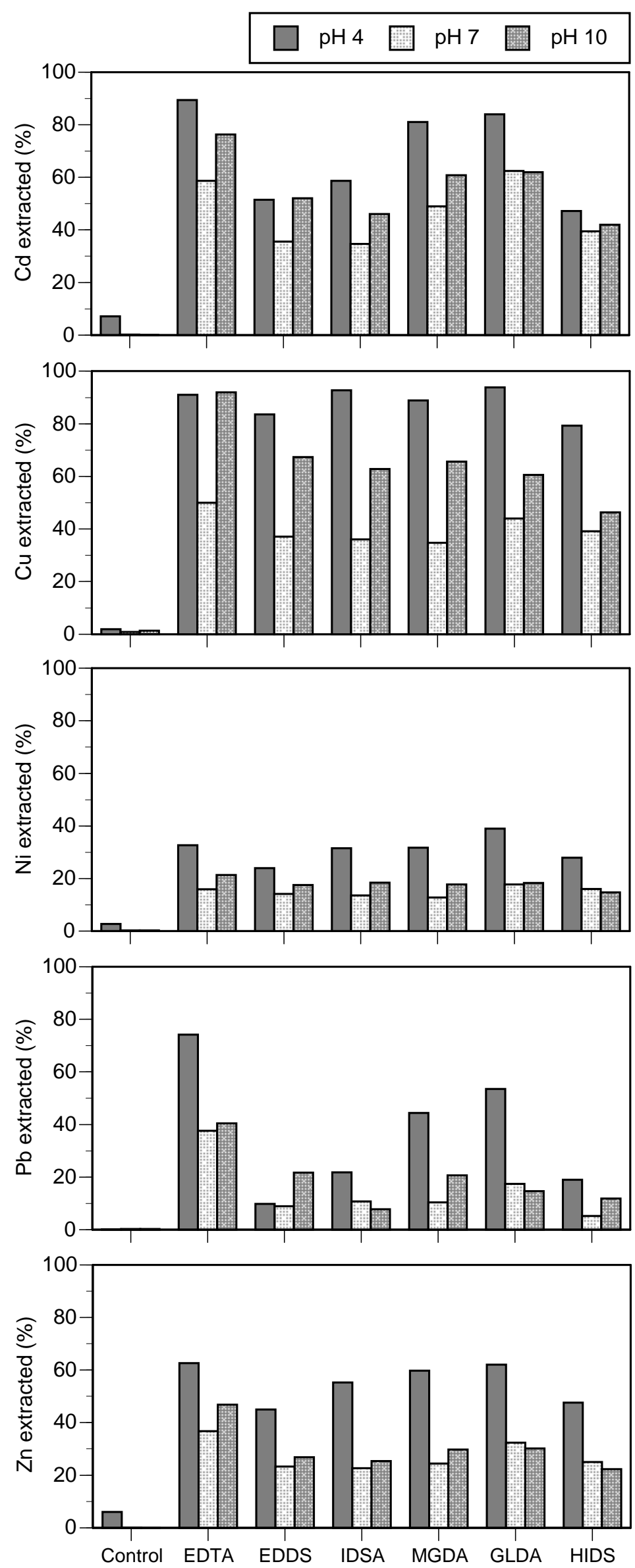

35 Figure 1. Extraction efficiency (\%) of metal ions $(\mathrm{Cd}, \mathrm{Cu}, \mathrm{Ni}, \mathrm{Pb}$ and $\mathrm{Zn})$ from the organic-rich soil 36 (BCR-700) as a function of $\mathrm{pH}$ with different chelants. 

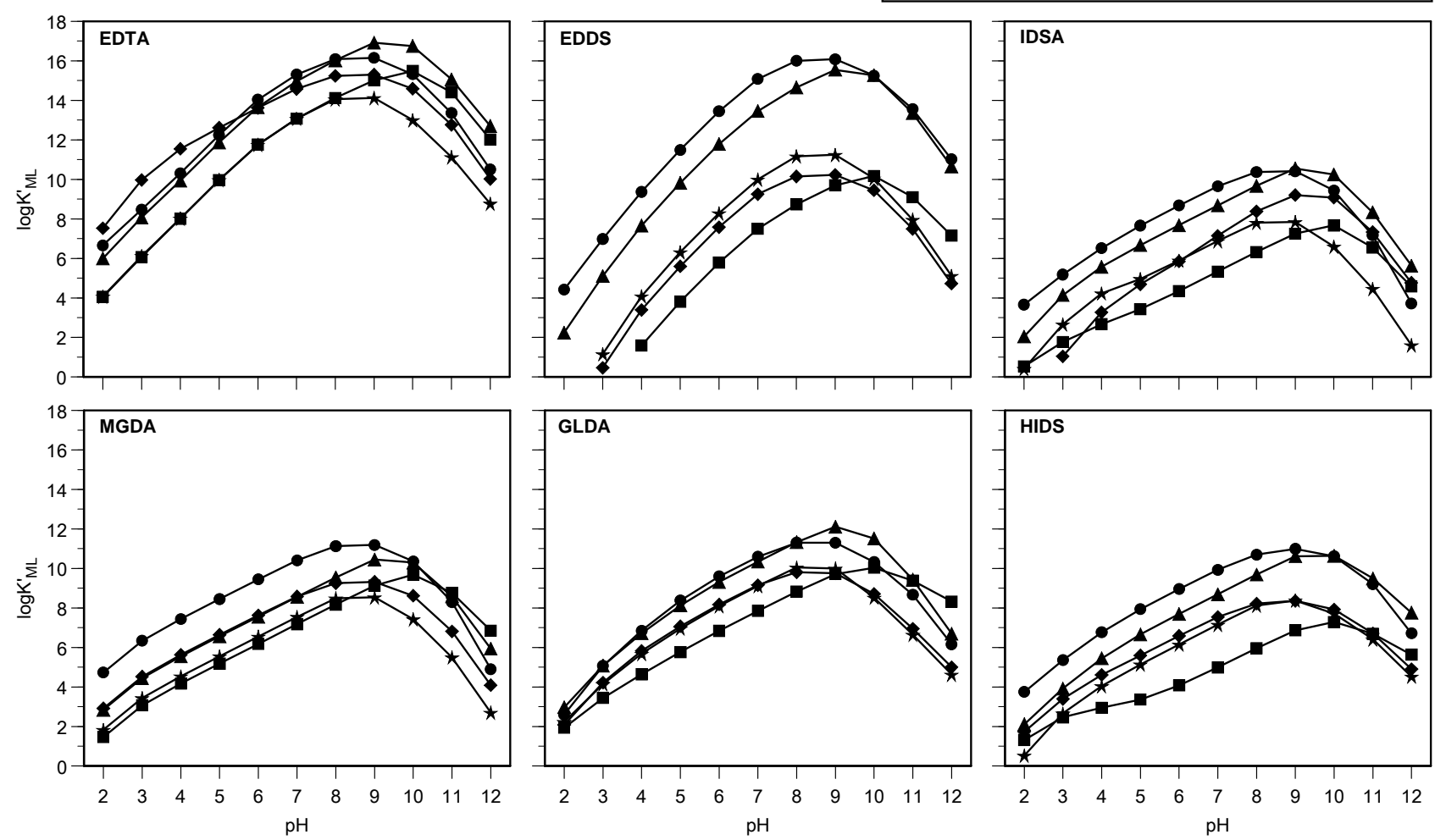

Figure 2. Conditional stability constants $\left(\log K_{M L}^{\prime}\right)$ for metal-chelant complexes of the chelants (EDTA, EDDS, IDSA, MGDA, GLDA and HIDS) with the metal ions (Cd, $\mathrm{Cu}, \mathrm{Ni}, \mathrm{Pb}$ and $\mathrm{Zn}$ ) as a function of $\mathrm{pH}$. 

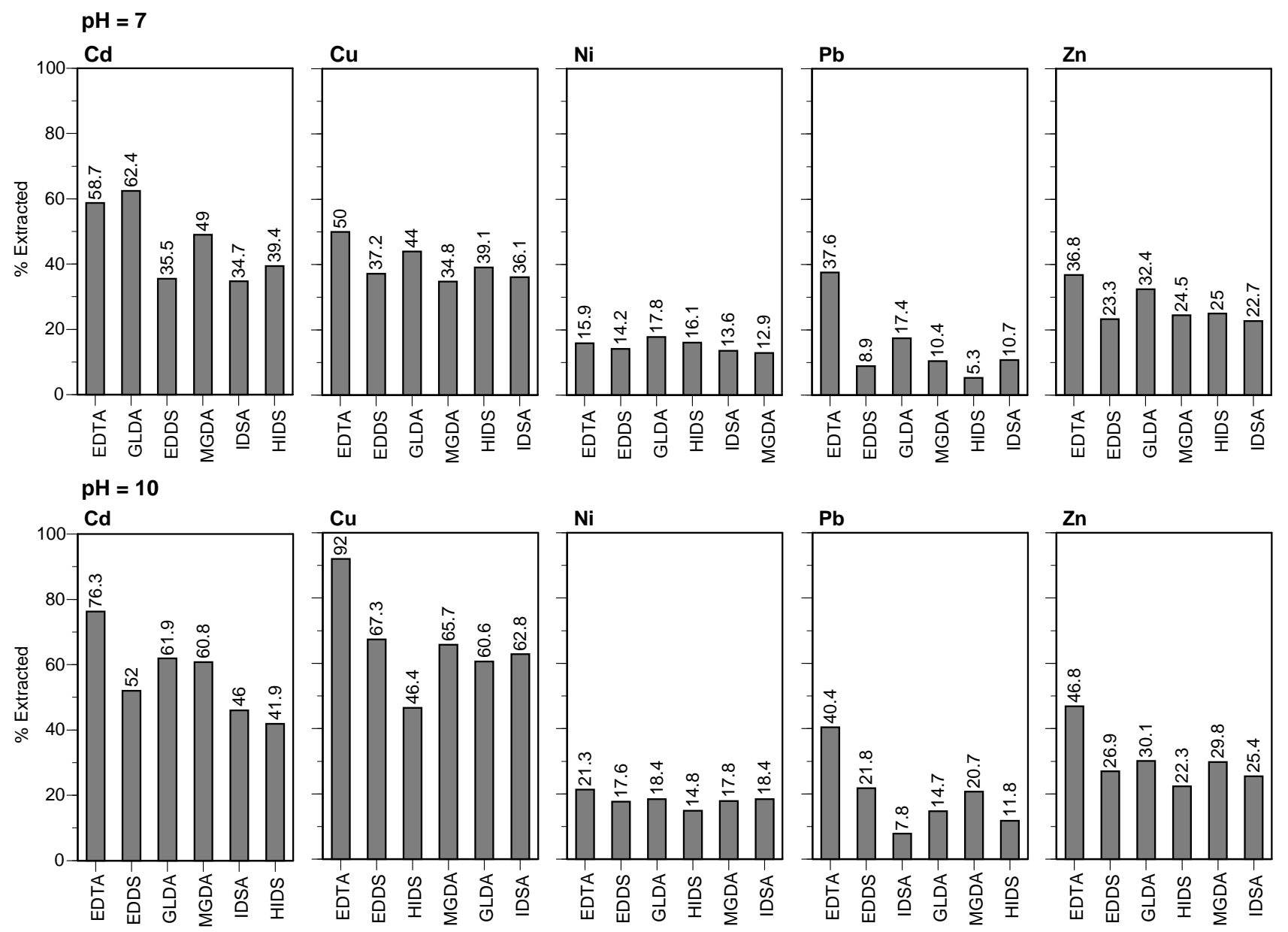

72 Figure 3. Comparative selectivity of the biodegradable chelants towards the metal ions in terms of

73 the conditional metal-chelant stability constants $\left(\log K_{\mathrm{ML}}^{\prime}\right)$. 

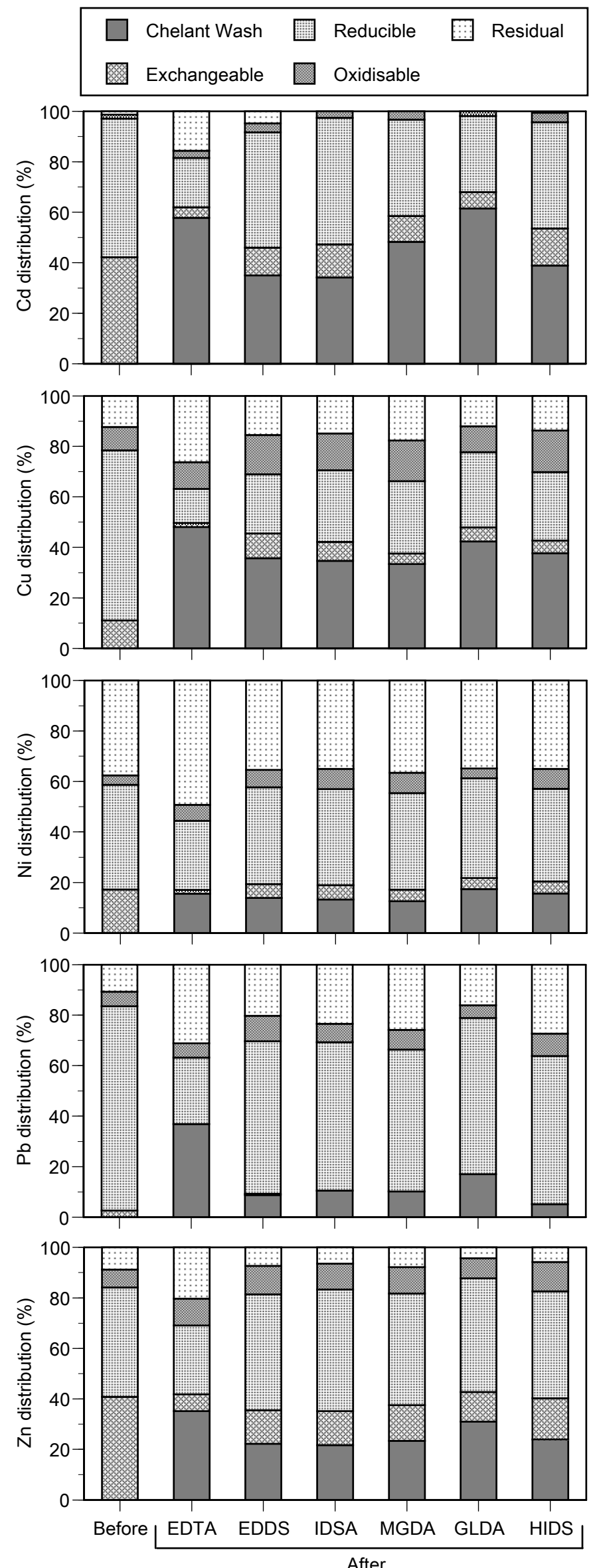

84 Figure 4. Comparative distribution of metal ions $(\mathrm{Cd}, \mathrm{Cu}, \mathrm{Ni}, \mathrm{Pb}$ and $\mathrm{Zn})$ in the solid phase of 85 organic-rich soil (BCR-700) before and after washing treatment with different chelants. 